\title{
Balloon Mitral Valvuloplasty (BMV) in Pregnancy: A Four- Year Experience at Shahid Gangalal National Heart Centre (SGNHC), Nepal
}

\author{
Regmi SR ${ }^{\star}$, Maskey A*, DUbey L*, Bhatt $Y^{\star}$, Malla R ${ }^{\star}$, Sharma D*, Rajbhandari R*, Limbu YR*, K.C. MB* \\ ${ }^{*}$ Department of Cardiology Shahid Gangalal National Heart Centre, Bansbari \\ Corresponding: Dr. Shyam Raj Regmi. \\ Shahid gangalal National Heart Centre, Bansbari, Kathmandu, Nepal Tel:00977-1-4371322, 00977-1-4371374. \\ Fax 00977-1-4371123 \\ Email: shyam_regmi2003@yahoo.com
}

\begin{abstract}
Balloon Mitral Valvuloplasty (BMV) has been performed safely during pregnancy with good results. This study was intended to see the efficacy and safety of BMW in this subset. Retrospective analysis of 22 pregnant women among a total of 861 patients who had undergone BMV for severe mitral stenosis at SGNHC from January 2003 to December 2007 were done. Mean fulroscopy time was $7.5 \pm 4.8 \mathrm{~min}$. post-BMV, the mean left atrial pressure dropped from $28.12 \pm 4.3 \mathrm{mmHg}$ to $15.32 \pm 6.4 \mathrm{mmHg}$. Mitral valve area as assessed by echocardiography increased from 0.76 $01770.21 \mathrm{~cm} 2$ to $1.8 \pm 0.26 \mathrm{~cm} 2$. all the patients showed symptomatic improvement. Six patients had an increase in MR by 2 grades. Twenty patients had a normal delevery while 2 underwent a caesarean section. There was no meternal morbidity or mortality in the peripartum period. On follow up for $26 \pm 15$ months, all babies maintained normal growth and development without any thyroid disease or malignancy. During pregnancy BMV is feasible, safe and effective. Maternal and fetal outcomes are excellent. Growth and milestone of development are not affected.
\end{abstract}

Keywords : Balloon Mitral valvuloplasty, Pregnancy, Mitral Stenosis

\section{INTRODUCTION}

Mitral stenosis (MS) primarily affects young women at reproductive age. Thus, pregnancy inMS patients is a common clinical problem in countries with high rheumatic disease prevalence like ours. MS contributes to significant morbidity in pregnancy. Pregnancy is associated with a $40-50 \%$ increase in cardiac outpur and a decrease ib systemic vascular resistance but, in the presence of severe mitral stenosis, these changes cannot occur. Untreated, the haemodynamic effects of mitral stenosis, together with the risk of thromboembolism, can lead to significanternal and fetal morbidity and mortality. For several decades surgical commisurotomy was being performed during pregnancy in patients with severe MS. However, BMV has been established as an effective method for treating MS in pregnancy with results comparable to surgical commisurotomy. Two BMV techniques have been extensively used: the inoue balloon technique and the transseptal over-the-wire balloon techniques. Studies to date have shown equal efficacy of the two BMV methods in terms of valve enlargement although the inoue approach is ismpler, faster, and yielded similar benefits and is also associated with a lower risk of creating severe mitral regurgitation. However, the efficacy and safety of BMV in our subset is not known. We designed this study to evaluated the safety of BMV for the treatment of MS in pregnant women.

\section{METHODS}

Patients:

Eight hundred and sixty one patient underwent BMV in Shahid Gangalal National heart centre (SGNHC) in past four years (from January 2003 to December 2007), out of whom 413
(47.97\%) were male and 448 (52.03\%) were female. Among them 22 were pregnant women with severe mitral stenosis at 24.2 \pm 4.6 weeks of gestation (20-37 weeks) and MS was diagnosed for the first time in all. Fourteen (63.64\%) were primigravidae and severe mitral stenosis was diagnosed during second (in six patient) and third (in two) pregnancy. The mean age was $23.6 \pm 4.2$ years. All the patients underwent BMV after 200 weeks of gestation (20-37 weeks, mean $24.2 \pm 4.6$ weeks), and all except two was in sinus rhythm. Sixteen (72.73\%) patients were in NYHA class II, and 6 (27.27\%) were in class III. Twelve patients had mild, and 10 patients had moderate or severe pulmonary arterial hypertension (PAH). MIld mitral regurgitation (MR) was present in 13 , mild to moderate MR in 7 and moderate MR present in 2.

\section{Statistical methods:}

Data for all cases were collected prospectively and analyzed using SPSS software. Data are reported as mean \pm SD. $\mathrm{P}$-values $<0.05$ were considered significant.

\section{Cardiac catheterization and BMV technique:}

$\mathrm{BMV}$ procedure under antibiotic coverage (Cefazolin) using local anaesthesia was done with an Inoue balloon with the standard anterograde transseptal techniue. The procedure was performed in the fasting state. Special shielding was used in all the patients with their abdomen wrapped from just below the diapharagm down to the pubic symphysis by lead shields $>0.5$ $\mathrm{mm}$ thickness. Femoral venous approach was used in all cases. Unfractionated Heparin (3000 IU) was given intravenously after trans-septal puncture. The method of balloon sizing was 
similar to that used in Inoue-balloon BMV and was based on body height.

Patients' clinical characteristics are shown in table 1.

\begin{tabular}{l|l|} 
Table 1. Clinical characteristics \\
\hline \multicolumn{1}{c|}{ Parameters } & \multicolumn{1}{c|}{$\mathrm{n}=22$} \\
\hline Age (years) & $23.6 \pm 4.2$ \\
\hline Gestation (weeks) & $24.2 \pm 4.6$ \\
\hline Mitral valve area (cm2) & $0.76 \pm 0.21$ \\
\hline Symptom class (NYHA) & \\
\hline Class I \& II & 16 \\
\hline Class III & 6 \\
\hline PAH & $7(44 \%)$ \\
\hline Mild & 12 \\
\hline Moderate to severe & 10 \\
\hline LA Pressure (mmHg) & $28.12 \pm 4.3$ \\
\hline MR Nil/Grade I/II & 13 \\
\hline Grade II/III & 7 \\
\hline Grade III & 2 \\
\hline
\end{tabular}

NYHA: New York Heart Association, PAH: Pulmonary Artery Hypertension, LA: Left Atrium, MR: Mitral Regurgitation.

\section{RESULTS}

The procedure was successful in all with no maternal mortality. Mean fluoroscopy time was $7.5 \pm 4.8 \mathrm{~min}$. post$\mathrm{BMV}$, the mean left atrial pressure dropped from $28.12 \pm 4.3$ $\mathrm{mmHg}$ to $15.32 \pm 6.4 \mathrm{mmHg}$. No patients was left with residual MS $(M V A<1.5 \mathrm{~cm} 2)$. Mitral valve area as assessed by echocardiography increased from $0.76 \pm 0.21 \mathrm{~cm} 2$ to $1.8 \pm 0.26$ $\mathrm{cm} 2$. all the patients had symptomatic improvement. Six patients had an increase in mitral regurgitation (MR) by 2 grades. One patient had a mild tear of the anterior mitral leaflet, others had excessive commissural MR. none of the 6 patients required mitral valve replacement. There was a significant reduction in the pulmonary artery pressure after BMV. Twenty patients had a normal delivery while 2 underwent a caesarean section. There was no maternal morbidity or mortality such as maternal death, abortion, or intrauterine growth retardation in the peripartum period. On follow up for $26 \pm 15$ months, all babies maintained normal growth and development without any thyroid disease or malignancy.

\section{DISCUSSION}

MS contributes to significant morbidity in pregnancy. Pregnancy is associated with a $40-50 \%$ increase in cardiac output and a decrease in systemic vascular resistance but, in the presence of severe mitral stenosis, these changes cannot occur. Untreated, the haemodynamic effects of mitral stenosis, together with the risk of thromboembolism, can lead to significant maternal and fetal morbidity and mortality. Large series of studies have proved the efficacy and safety of BMV in pregnant women with MS. As reported in other studies, in our series BMV produced impressive semodynamic improvement including a decrease in left atrial and pulmonary artery pressure, and an increase in mitral valve area. Most of our patients had an ideal anatomy of mitral valve for BMV.
Very few complications have been reported with balloon mitral commissurotomy during pregnancy. Mitral regurgitation was increased by grade 2 in six patients in our series but none required to undergo mitral valve replacement. In one report, one patient had a spontaneous abortion. There were no maternal deaths in our series, in contrast, mortality from surgical closed mitral commissurotomy was reported to be as high as $3 \%$ and that from open commissurotomy reached $5 \%$.

Fluoroscopic radiation exposure carries a potential risk to the unborn child. However, the risk is greatly diminished by appropriate and complete abdominal lead shielding, a short radiation exposure time, avoidance of left ventricular angiography, and performance of the procedure after the 14th week of gestation, when organogenesis has already been achieved. We, moreover, used Inoue balloon technique which seems to shorten the fluoroscopy time compared to the double balloon technique. In our study no baby had abnormalities related to radiation. Uneventful full term delivery was obtained in all patients, vaginally in 20; caesarean section was required in only two patients for obstertricc reasons. There was no fetal death or preterm delivery. On follow up for $26 \pm 15$ months, all babies maintained normal growth and development with no relative growth retardation. As yet, however, the long term outcome in these children remains unknown, since the future late appearance of radiation side effects cannot be excluded, though it must be very unlikely. Griem et al, in a 20 year follow up study of 1000 women irradiated for radiopelvimetry at much higher doses (15 to $30 \mathrm{mSv}$ ), found no difference in the incidence of cancer in comparison with a control group.

\section{CONCLUSION}

In conclusion, BMV in pregnancy leads to marked symptomatic relief along with no immediate detrimental effects of radiation on the fetus. Thus, BMV in pregnancy is safe, feasible and effective even in the newly emerging cardiac center like ours.

\section{REFERENCES}

1. Metcalfe J,Ueland K.Maternal cardiovascular adjustments to pregnancy. Prog Cardiovasc Dis 1974;16:363-74.

2. Turi ZG, Reyes VP, Raju S, et al. Percutaneious balloon versus surgical closed commissurotomy for mitral stenosis: A prospective randomized trial. Circulation 1991;83:1179-1185.

3. Reyes VP, Raju BS, Wyanne J, et al. Percutaneous balloon valvuloplasty percutaneious balloon valvuloplasty compared with open surgical commissurotomy for mitral stenosis. N Eng J Med 1994;331:961-967.

4. Hung JS, Chem MS, Wu JJ, et al. Short- and long-term results of catheter balloon percutaneous transvenous mitral commissurotomy Am J Cardiol 1991;67:854-862.

5. Esteves VA, Ramos AIO, Braga SLN. Harrison JK, Sousa JE. Effectiveness of percutaneous balloon mitral valvotomy during pregnancy. Am J7 Cardiol 1991;68:9304

6. Knapp RC, Ardin LI. Closed mitral valvlotomy in pregnancy. Clin Obstet Gynecol 1968;11:978-91.

7. EL Maraghy M, Abou Senna I, EL Tewehy F, Bassioni M, Ayoub A, EI Sayed H. Mitral valvotomy in pregnancy. Am J Obset Gynecol 1983;145:708-10.

8. Vosloo S, Reichart B. The feasibility of closed mitral valvotomy in pregnancy. J Thorac Cardiovasc Surg 1987;93:675-9.

9. Zitnik RS, Pregnancy and open heart surgery. Circulation 1969;39:1257-62. 
10. Szekely P, Snaith L. The place of cardiac surgery in the management of the pregnant women with heart disease. J Obstet Gynecol 1973;70:69-77

11. Becker RM, Intracardiac srugery in pregnant women with heart disease. J Obstet Gynecol 1973;70:69-77

12. Becker RM. Intracardiac Surgery in pregnant women. Ann Thorac Surg 1983;36:453-8

13. Bernal JM, Mitralles PJ. Cardiac surgery with cardiopulmonary bypass during pregnancy. Obstet
Gynecol Surv 1986;41:1-6

14. patel \}J, Mitha AS, Hassen F, Patel N, Naidu R, Chetty S, et al. Percutaneous balloon mitral valvotomy in pregnant patients with tight pliable mitral stenosis. Am Heart J 1993;125:1106-9.

15. Griem ML, Meier P, Dobben GD. Analysis of the morbidity and mortality of children irradiated in fetal life. Radiology 1967;88:374-9. 